\title{
Formas de vida en el sueño de la ciudad. 0 cómo la arquitectura se convierte en el pastor del imaginario colectivo
}

\author{
Carlos Tapia Martín y Jorge Minguet Medina \\ Universidad de Sevilla y Universidad de Málaga \\ tava@us.es; jminguet@gmx.es
}

RESUMEN: No es común analizar la ciudad y la arquitectura contemporáneas desde la noción de «sueño» y, sin embargo, un rastreo minucioso detecta en la historia de la arquitectura toda una batería de síntomas no metafóricos del sueño, compartiendo escenario con la acción del neoliberalismo que induce en las sociedades deseos como lo ha hecho en la historia la religión. Los humanos, que comparten ese escenario con otros seres, no humanos, se vuelven dóciles y sus problemas no se derivan de sus actitudes, sino que, a su vez, tienen «vida» propia, intratables. El artículo, para expresar cómo se convierte la arquitectura en pastor del imaginario colectivo, esgrime que los arquitectos ya no son ni demiurgos ni marionetas, como decía Lefebvre. Son pastores de esta religión de sueños individuales soñados por la ciudad que, a su vez, sueña, como forma de vida autónoma, la forma de vida de sus moradores.

PALABRAS CLAVE: Sueño; Formas de vida; Antropomorfismo; Arquitectura; Neoliberalismo; Imaginario colectivo.

\section{Ways of Life in the Dreams of the City. Or How Architecture Becomes the Shepherd of the Collective Imagery}

ABSTRACT: Analysis of the contemporary city and architecture from the notion of "dreaming" is uncommon. However, in the history of architecture a thorough search detects a whole battery of non-metaphoric symptoms of sleep, sharing the stage with the neoliberalism action that induces desires in societies as religion has done in history. Humans, who share this scenario with other, not human, beings become docile and their problems no longer derive from their attitudes, but in turn, have their own, intractable «life». To express how architecture becomes the herdsman of the collective imagery, the article argues that architects are no longer demiurges or puppets, as Lefebvre intimated. They are the shepherds of this religion of individual dreams dreamt by the city that in turn dreams, as an independent form of life, about the way of life of its inhabitants.

KEYWORDS: Dream; Life Forms; Anthropomorphism; Architecture; Neoliberalism; Collective imaginary.

Recibido: 23 de febrero de 2020 / Aceptado: 7 de junio de 2020.

\section{Introducción}

[Narrador, voz en off, presentando la película: Habla la ciudad de Chicago]

Soy la ciudad, el corazón abierto de América, el crisol de todas las razas, credos, colores y religiones de la humanidad. Desde mis famosos corrales hasta mis imponentes fábricas, desde mis barrios humildes hasta el elegante Lakeshore Drive, soy la voz, el latido de esta gigante y expansiva, sórdida y hermosa, pobre y magnífica ciudadela de la civilización. Y esta es la historia, solo una noche en esta gran ciudad.

\footnotetext{
Cómo citar este artículo: TAPIA MARTíN, Carlos y MINGUET MEDINA, Jorge, «Formas de vida en el sueño de la ciudad. O cómo la arquitectura se convierte en el pastor del imaginario colectivo», Boletín de Arte-UMA, n. ${ }^{\circ} 42$, Departamento de Historia del Arte, Universidad de Málaga, 2021, pp. 189-199, ISSN: 0211-8483, e-ISSN: 2695-415X, DOI: http://dx.doi.org/10.24310/BoLArte.2021.vi42.8029
} 


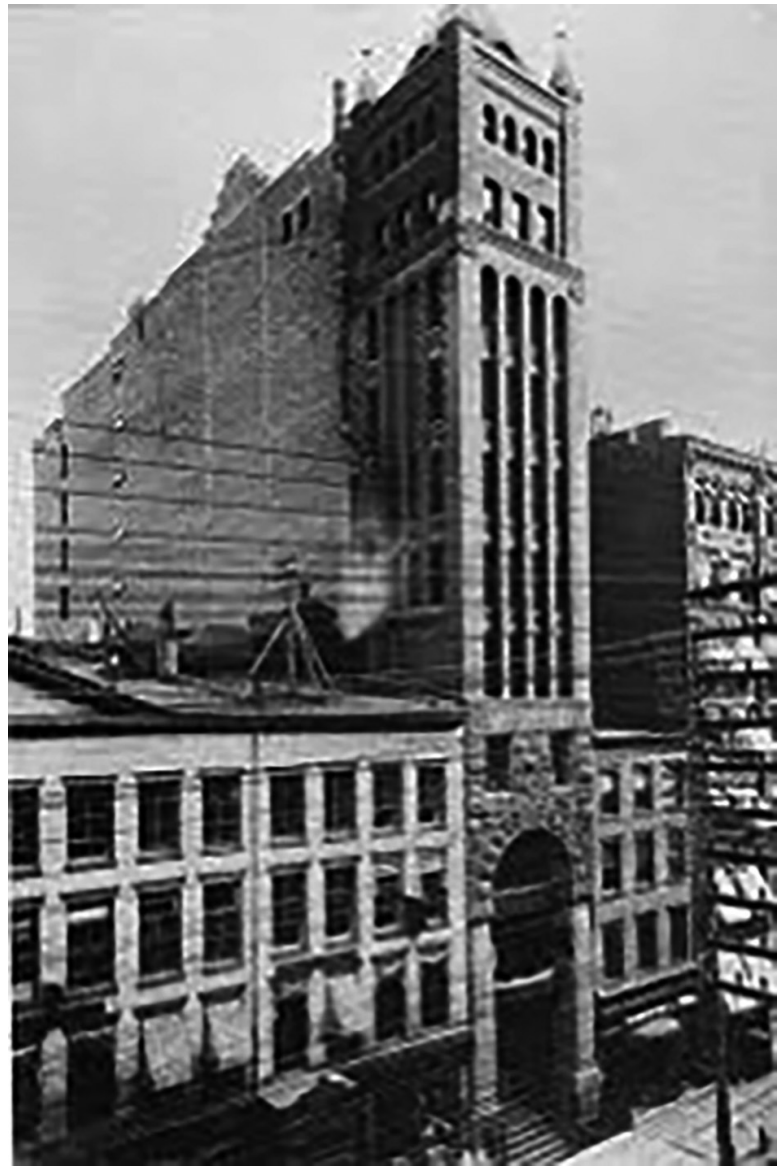

1. Tower Building. 1889-1914. Bradford Gilbert

Ahora conozcan a mis ciudadanos [...]

[narrador en off, concluyendo la película: La ciudad de Chicago se personifica como una forma de vida superior]

[...] mientras que otros se están levantando para ir a trabajar [...] pues en todas partes cada minuto de cada hora [...] en este crisol de cada raza, credo, color y religión en la humanidad [...] la gente está trabajando, riendo y muriendo; algunos, como Johnny Kelly [...] nacen de nuevo [...] en la ciudad que nunca duerme.

City That Never Sleeps. John H. Auer, 1953

Introducción (al sueño, lúcido)

La arquitectura no ha dado crédito suficiente a la noción de «sueño» como síntoma de contemporaneidad. Cuando usa el término, aún se liga a concepciones utopistas, o se hunde en un rasgo que no es puramente arquitectónico, sino de cumplimiento de deseos de todo aquél que intente cambiar su tiempo. Una consabida aspiración de la arquitectura es ser un continuo cambio -insistente rasgo de lo moderno- y, por tanto, se expresa ante un difícil desafío como ese con metáforas o hipérboles, como la de conseguir los sueños inalcanzables.

La legitimidad del soñador que aspira a un logro, sea de superación personal, sea de aporte al género humano, no es, sin embargo, un asunto inocente y apreciable con consciencia por las sociedades. La historia de la arquitectura está acompañada por un sinfín de connotaciones de su acción por la noción de sueño, lo cual no impide que al mismo tiempo sea la palabra que el neoliberalismo, como hipnotizador, sabe pronunciar para activar en cada ser una actitud previamente inducida. Tal actitud imposibilita crítica alguna al sistema dado que no hay percepción de crisis.

Esta ceguera es, traducida la acción arquitectónica en generación de ciudad, una forma de manifestar por nuestra parte la indefinición del ente que se invoca cuando se habla de los problemas urbanos. Aparece como sueño, donde la complejidad de las tramas, de las estructuras imposibles de resolver, son solo comprensibles en un entorno de perspicacia equivalente. Es una ensoñación -reverie 1 - como logro y una ensoñación como ente amorfo con vida propia, inasible y nunca del todo entendible. Las sociedades, ligadas ya a la ciudad -no queda prácticamente nada de la antigua dualidad campo/ciudad- se complejizan en una sobresaturación de información que se presenta equivalentemente como eslóganes (I have a dream, «dicho» por Nike) y por formas de vida (The city that never sleeps, Dreamcity, Dreamland, Dreamscapes, etc.) [1].

No eran los arquitectos, sino que pertenecía al cenáculo de los etnólogos revelar -para las organizaciones humanas que nuestro naturalismo llamaría societarias- una suerte de clarificación de doble vía a la pregunta sobre cómo son las agrupaciones humanas por la complejidad de sus estructuras.

Por un lado, tal revelación se debería considerar como desmitificadora para aquellos grupos humanos de los que se tomaban la pureza y esencialidad de sus cláusulas y, por su parte, liberadora, al trascender la posibilidad de lo irracional, para aquellos otros cuyas cosmovisiones habían jugado el 
papel de instancias coercitivas por obediencia al positivismo. De las primeras, tildadas como primitivas por las segundas, se extraen raigambres de pertenencia a la Tierra que implantan en esas últimas una consciencia colectiva «ecológica» como nuevo mantra fundacional para la reorganización o renovación de las sociedades.

Con el plural -no se trata de un problema local, de una sola sociedad, sino que cada sociedad invoca su pertenencia en la globalización- se hace constar que sociedades cualesquiera en cualquier lugar podrían asumir consumos de recursos responsables, vida en comunión con la Tierra, etc., al modo en que aquellas comunidades más distantes al capitalismo muestran en su (relativa) excepcionalidad. A los escenarios imaginarios que de ello se derivan, se les llama sueños, utopías o fantasmagorías (Sloterdijk y Turner, 2018: $48)^{2}$, y vamos a tratar de demostrar aquí que no son tan raros esos oscuros preceptos en la historia (moderna) de la arquitectura y de las culturas occidentales pero que, al mismo tiempo, hay una no menos oscura confusión en su empleo.

A pesar de que el sueño y sus distintas escalas de entendimiento y representación ha acompañado a esa humanidad que progresa, su crédito no ha sido objeto de aprecio en las culturas occidentales más que como extravagancias, no reintegrables como producción de conocimiento. Sin embargo, hoy se admite su empleo en cualquier ámbito (cultural, académico, político, económico, etc.).

\section{El sueño en forma: de moderna inhumana a antropomórfica posthumana}

La estricta racionalidad de la Modernidad, la cientificidad en todo discurso, el rigor académico como justificación de lo existente, ha compartido siempre escena con otras formas de comprensión, donde la parte de lo humano más irracional reclamaba su proporción de legitimidad. En la pugna de lo apolíneo contra lo dionisíaco, el balance arrojaba, hasta ahora, solvencia para lo exacto y comprobable, incluyendo el Proyecto Arquitectónico, salvo para el tiempo futuro, en el que se canalizaban los anhelos a partir de especulaciones, ficciones o sueños. Lo que hoy detectamos es una exacerbación en este proceso, donde los sueños inducidos son una estrategia más del neoliberalismo ${ }^{3}$, que debe rodearse de síntomas reconocibles para una completa eficacia. Una vez que la indi- ferenciación entre sueño y deseo se ha producido, y que podemos hacer desear al colectivo con técnicas para conjurar la frustración por la división del trabajo en el marco de las culturas del espectáculo y de consumo de masas, las sociedades se tornan dóciles y sus problemas no se derivan de sus actitudes, sino que tienen «vida» propia, intratables.

Los síntomas necesarios para encontrar plausible que lo cotidiano tiene la misma estructura que un sueño se hallan en cualquier parte. Uno de los sueños de T. W. Adorno más famosos, que trascribió su esposa, ponía a bailar al filósofo con un perro gran danés vestido de chaqué, y serviría para ejemplificar cómo lo incomprensible se torna real.

Desde el momento en que recientemente ${ }^{4}$ hemos exacerbado en Occidente la causalidad que humaniza cada exterioridad a ella misma (esto es, el antropomorfismo), la división entre razón y sinrazón -el día y la noche en términos ilustrados-, ya no más es un límite sino un desafío que desdibuja el antagonismo de juicio frente a enajenación. Los animales bailan y hablan (Berger, 2015) o, mejor, nos hablamos con ellos, en una ampliación de la comprensión animista de esas sociedades sobre las que Occidente, en sus cenáculos, trata de reencontrarse con ellas (Descola, 2008). No solamente le hablamos a nuestro gato -y todos nuestros gatos han sido engendrados por Grandville (Stahl y Grandville, 1877)- esperando que cumpla nuestros requerimientos, sino que no habría extrañeza al averiguar que tienen una vida secreta donde entre sí conforman una sociedad no muy diferente de la nuestra. Ello redelimita lo que conocemos como formas de vida puesto que la animalidad multiplica la definición de lo humano, como lo hacemos igualmente cuando se socializan las máquinas hasta el punto de ya no poderlas llamar así, nos atemorizan las respuestas de códigos informáticos, ya domésticos, o las ciudades hablan. Son atributos de animalidad tendentes a la confusión con lo humano, que ya no está compuesto de seres con origen común.

Sueño y animalidad están íntimamente relacionados cuando imaginamos que nos despertamos en el futuro, que cada vez es más presente. Derrida (2008), a propósito de la cuestión del despertar en el Heidegger ${ }^{5}$ de "Ser y Tiempo", correlaciona tal cuestión con la del sueño, que, a su vez, es indisociable de la del animal. El despertar es aquí «dejar que despierte lo que duerme». De ello deduce que la distinción entre la vigilia y el sueño es una redefinición de los lugares para saber qué es consciencia y qué lo inconsciente: lo que 


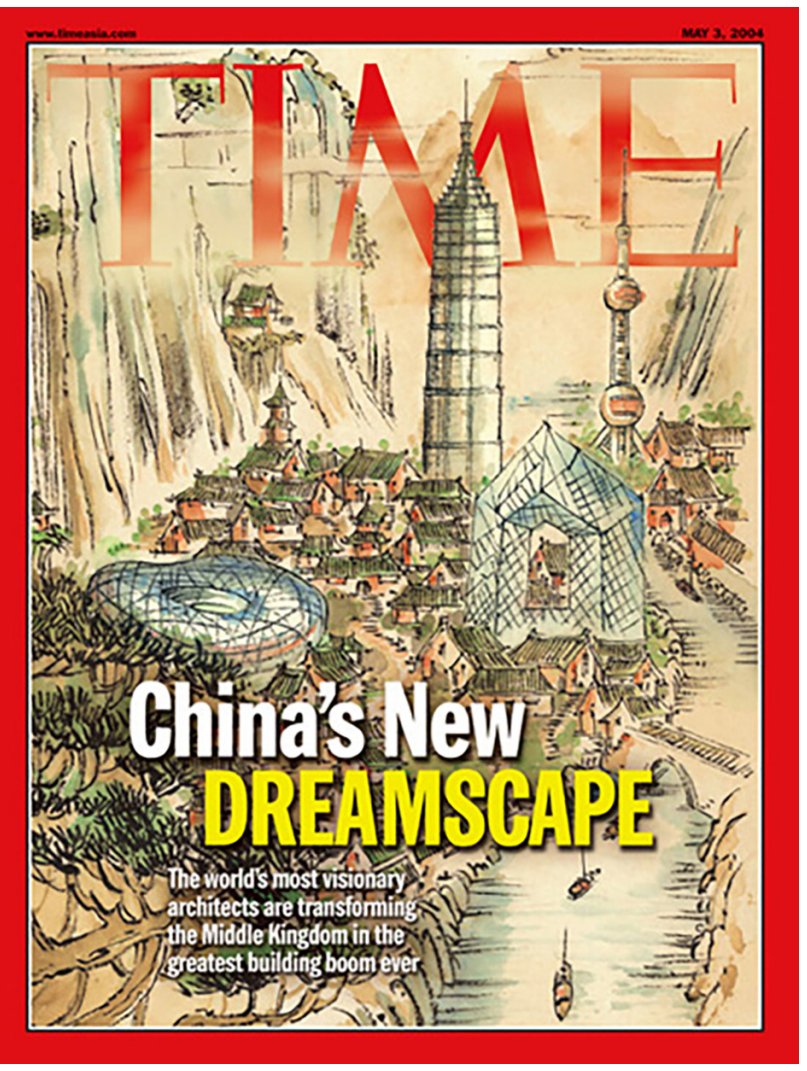

2. Revista Time, China's New Dreamscape, 2004, vol. 163 \#18

Heidegger denomina vigilia no es la consciencia, así como lo que denomina sueño no es el inconsciente.

En la película City That Never Sleeps (1953), la ciudad de Chicago habla en primera persona de sí misma y de sus ciudadanos, seres dependientes de la morfología urbana, y de la verdadera naturaleza de ese ser-entidad-deidad que tiene consciencia de sí y que no interfiere en cómo sus ciudadanos viven y tienen sus propios sueños individuales. En todo caso, si existe inferencia del todo a la parte, es porque la articulación de las partes, el colectivo, proyecta sus sueños en la forma urbana y la inconsistencia característica del sueño tiene consecuencias para la arquitectura y el diseño urbano. Chicago sueña los sueños de sus ciudadanos ${ }^{6}$. Aquí soñar equivale a construir, en el presente, lo imposible. Lo imposible es superar el reto de la altura de los edificios, lo imposible es que sus ciudadanos logren renacer.

La dimensión e idiosincrasia de ciudades como Chicago difieren de las de otras ciudades-seres por cuanto «él» (imasculino!) ${ }^{7}$ representa, encarna, una continuidad de las ensoñaciones de la noche en el día. Aquella prohibición por la que los humanos no podían ser por naturaleza lo que por descontado son por naturaleza, queda constituida como nueva religión, lo cual quiere decir que desear que se cumpla lo imposible ya está en las homilías de los sacerdotes laicos. Soñar equivale a desear, aunque sepamos que no es lo mismo, gracias a Deleuze ${ }^{8}$. A los creyentes, esos humanos que arriban al mundo con una misión, debe considerárseles seres especiales (por sus ciudades, naturalmente). Se peca si se cede ante la dificultad de la empresa: cualquiera debe soñar con ser presidente de los Estados Unidos, se sueña América tanto como se sueña China ${ }^{9}$. En su credo, la omnipotencia de la voluntad humana no tiene reparos a la hora de homologar en vigilia lo que provee el sueño [2].

\section{Polis soñadora y deseo}

La expansión de esta religión no tiene control, ni pide reservas para adscribirse. Todos entran y es que todos deben entrar en los nuevos incubatio ${ }^{10}$. Así, el cenáculo (Lefebvre, 2018: 135) de los etnólogos ya no es el lugar reservado a los iniciados, sino que se abren a diario sucursales onirológicas en cualquier lugar. Como ejemplos sirvan, en el más puro contexto científico, los wearables del MIT, Dormio ${ }^{11}$, para el control del sueño o Neuralink ${ }^{12}$ y sus investigaciones sobre el sueño dentro de las empresas de Elon Musk. Ello demuestra que aquellas categorías o claves analíticas menospreciadas por la Modernidad son objeto de interés, por su función catártica, supuestamente emancipadora. Sin embargo, el asalto al último reducto que significaría el sueño como lo indispensable de la imaginación para la supervivencia colectiva es patente (Crary, 2013). Se trata de reintegrar el sueño en el sistema y sin salir del laboratorio moderno.

La oscura equiparación de sueño con deseo para la manipulación del imaginario colectivo y el sometimiento a un sistema basado en promesas no solo se acepta para la acción arquitectónica, sino que juega un papel determinante en las ciudades que se sueñan a sí mismas ${ }^{13}$. Según Lefebvre, los arquitectos desempeñamos el papel de demiurgos y marionetas al mismo tiempo. Si, siguiendo la pregunta de la novela de Dick, "¿Sueñan los androides con ovejas eléctricas?», pensar nuevas formas de vida en colectivos de 
3 y 4 . At the Time of the Louisville Flood, Margaret Bourke-White, 1937 y King's Dream of New York, ilustración de Richard Rummell para el libro homónimo de Moses King, 1915

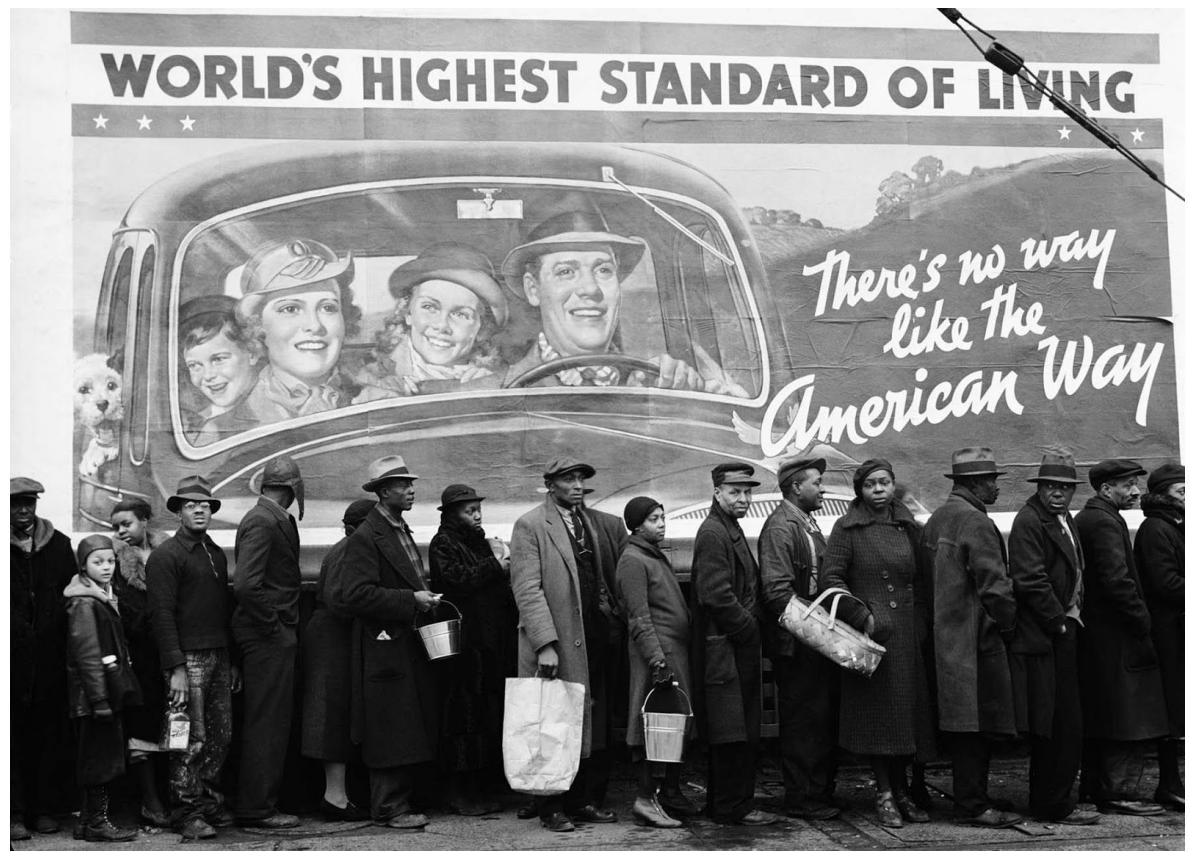

humanos y no humanos requiere pastores (en el pleno reconocimiento religioso del término), los arquitectos hemos de repensar esos dos roles [3] y [4].

¿Las ciudades sueñan con nuevas formas de vida?

Una noche, Zhuangzi soñó con ser una mariposa, una mariposa feliz, presumiendo y haciendo las cosas que le gustaban, sin darse cuenta de ser Zhuangzi. De repente se despertó, somnoliento, Zhuangzi otra vez. Y no podía decir si había sido Zhuangzi quien había soñado con la mariposa o la mariposa que soñaba con Zhuangzi ${ }^{14}$.

El tránsito animalidad-humanidad que transmuta en una hibridación de las distinciones clásicas de los seres merece ser llevado al extremo en la confusión de equiparar la ciudad con sueño, como ciudad que se sueña, o concebir si es la ciudad la que nos sueña, como sujetos con una intencionalidad en ella.

Nuestro imaginario colectivo ya se permite tratar a los edificios como seres. Es fácil acordarse de las personificaciones de los edificios en Hedjuk (1985), Koolhaas (2014) o Vriesendorp ${ }^{15}$. Añade peso que Moneo publique un libro titu-

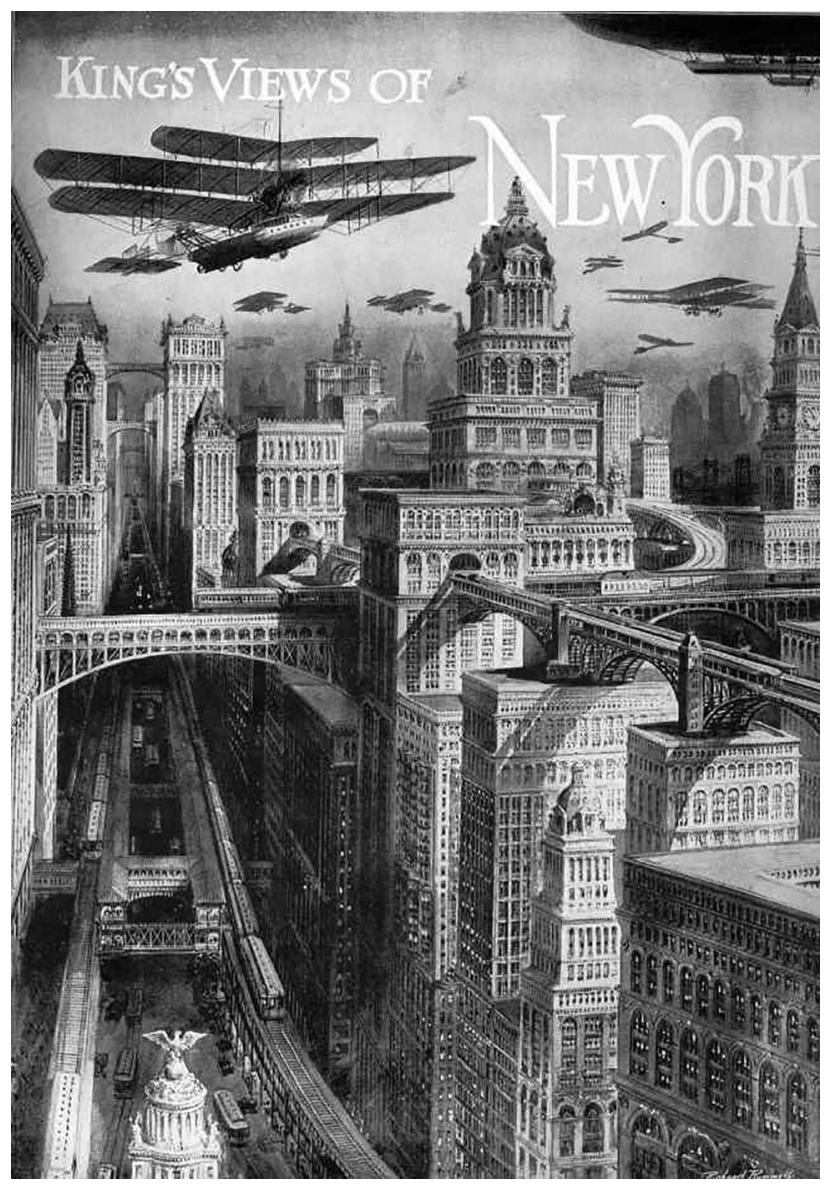




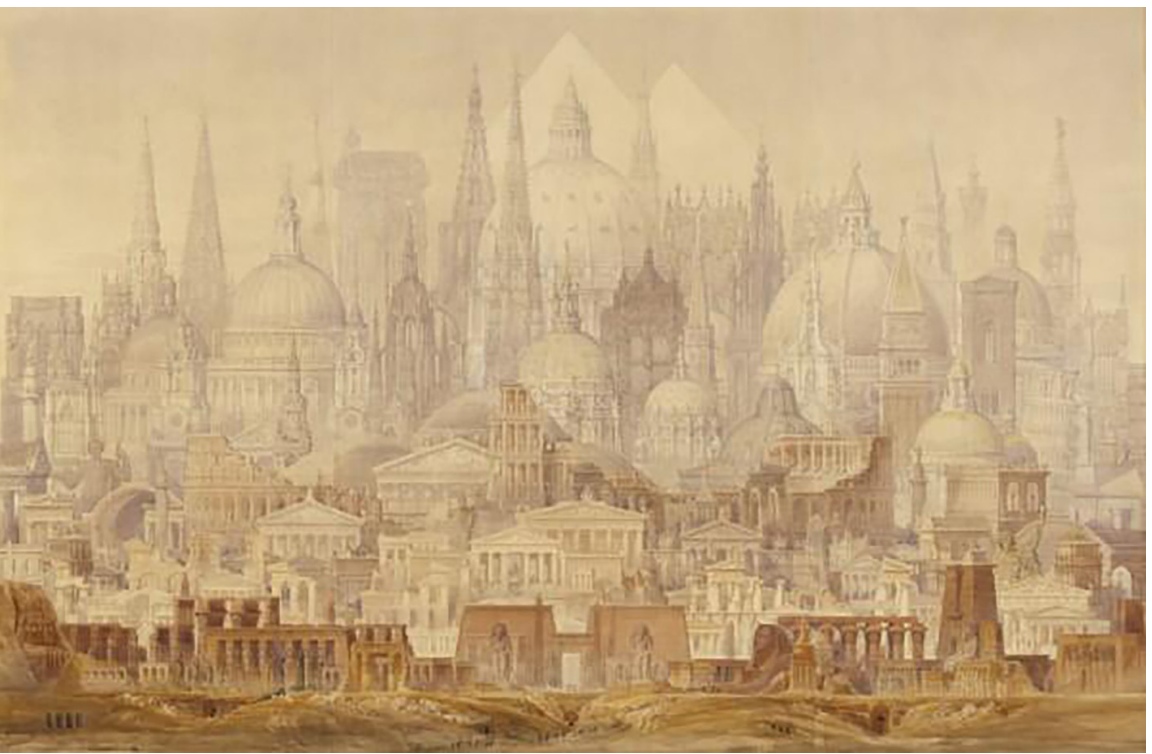

5. The Professor's Dream

1848. Charles Robert

Cockerell (1788-1863) lado La vida de los edificios (2017) o la favorable crítica al trabajo de Edward Hollis La vida secreta de los edificios (2011).

Imitando el proceso de transmutación de la animalidad en humanidad y su extensión hasta disolver la diferenciación entre sujeto y objeto (Latour, 2007), trataremos de explicar un proceso análogo, obligadamente conciso, respecto a la arquitectura y el sueño. Primero, ejemplificaremos el recorrido del sueño, uno de tantos, yendo del pastor a la ciudad.

En $1884^{16}$, en el 52 de Broadway en Nueva York, cerca de Wall Street, un posteriormente llamado rascacielos con solo ocho pisos, construido en acero, fue un hito notable en el imaginario colectivo, no solo para la ciudad de Nueva York, sino también para los sueños del resto de ciudades alrededor del mundo. Nacido después de un sueño (Korom, 2008), como dijo su autor, B. L. Gilbert, con su nacimiento inauguró la genealogía irracional de un linaje arquitectónico que se define como onírico. Unos 45 años antes, el reconocido arquitecto Ch. R. Cockerell había pintado El sueño del profesor, en 1848, reivindicando su edad historicista, al ensamblar el impulso hipnagógico del libro Hypnerotomachia Poliphili de Francesco Colonna, dentro de la psique arquitectónica desde 1499. La pintura de Cockerell, así como la de El sueño del arquitecto ${ }^{17}$ (1838) de Thomas Cole, no se centró en la arquitectura, ni en un arquitecto, sino en El Arquitecto, descansando en la concepción humanista del Hombre apoyada por la acumulación de conocimiento [5].
La fascinación de la arquitectura por el sueño no se retrotrae a tiempos que ya no nos pertenecen, sino que son actualidad. Recordemos algunos sueños como argumento proyectual de arquitectos conocidos como Utzon ${ }^{18}$, Krier\&Scolari $^{19}$, Archigram $^{20}$, Tigerman ${ }^{21}$, Lacaton\&Vassal ${ }^{22}$, RCR $^{23} \mathrm{O}$ Ingels ${ }^{24}$. Sin embargo, desde el «Tower Building», creado por Gilbert, hasta la propuesta académica del famoso arquitecto chino Ma Yansong para reconstruir el World Trade Center en Manhattan, inspirada en una nube aparecida en un sueño tras varias noches de pesadillas desesperadas, soñar juntos se ha convertido en el último asalto del «neoliberalismo realmente existente" como Neil Brenner y Nik Theodore (2002) nombran a las últimas creaciones del capitalismo tardío. China no es ajena a esta destrucción creativa. Como prueba de ello, recuérdese el Proceso Infrarrojo -Infrared process- (Koolhaas et al, 2001). Basado en el sueño americano y descrito por Koolhaas 45 años después, su antecesor americano es una mala siesta tras una comida copiosa en comparación con el sueño chino compuesto por su líder supremo Xi Jinping. Trump lo sabe, e induce al éxtasis por hipnosis a los creyentes en la fe de su American Way of Life con su retórica y acciones, injustificables solo si uno es lúcido como para acreditar que se vive un sueño. Quienes no tienen derecho a ese sueño, los emigrantes ilegales en territorio norteamericano, paradójicamente se autodenominan «dreamers» [6] y [7]. 
En segundo lugar, y superando lo anterior, debe tratarse la autoconsciencia del sueño colectivo de los ciudadanos cuando la ciudad se personifica y habla. Según el referido texto de Žižek, que Zhuangzi sueñe que es mariposa es factible. Pero no es posible lo contrario. La mariposa jamás tendría consciencia de sí para soñar ser Zhuangzi, como ha querido demostrarse por Bentham, Singer o el papa Juan Pablo II.

Con todo, este es el gran logro de la ciudad que sueña: todas las acciones de sus ciudadanos no son nada en comparación con la autonomía que adquiere como forma de vida. La mariposa (animal) ha conseguido la simetrización de la consciencia a partir del sueño. La ciudad, como traductora fiel del imaginario colectivo, sus formas, espacios, pero también sus usurpaciones, desigualdades, marginaciones, constituye la continua discontinuidad que caracteriza el soñar. Alvin Boyarsky (1968), al estudiar la ciudad de Chicago al final de los 60 ofrece una descripción perfectamente ajustable a nuestros supuestos: «Adoptados psicológicamente por los armónicos y las asociaciones de un entorno agresivamente ensamblado de elementos que chocan simultáneamente, imágenes deformadas y multiplicadas, restringidas por redes geométricas superpuestas, edificios como máquinas gigantes, que contienen dentro de sí mismos la arquitectura del entorno que los rodea, son percibidos en estados sucesivos por primitivas de una nueva sensibilidad que ha sido completamente revisada» ${ }^{25}$. Si comparamos esta definición con lo que se expresa en el film de Auer de 1953, cabe poco margen para que sean criticados nuestros supuestos como meros juegos metafóricos académicos.

En tal personificación, la carga de responsabilidades, la toma de decisiones, los objetivos a cumplir no atienden a los ciudadanos, sino a la detección de los imaginarios colectivos. Ahondar en ellos desde la erección del rascacielos de Gilbert, es la misión de los arquitectos. Walter Benjamin dijo que de lo que se trata es de observar el conjunto de las cosas ordenadas como si lo hubiera compilado la no-forma del sueño en su voluntad lujuriosa, indescriptible, irreprochable.

\section{Conclusiones. ¿Cómo se convierte la arquitectura en pastor del imaginario colectivo?}

Según C. Castoriadis (Castro, 1988: 40-46; 1997)²6, un imaginario, usemos el ejemplo del imaginario capitalista, por su-
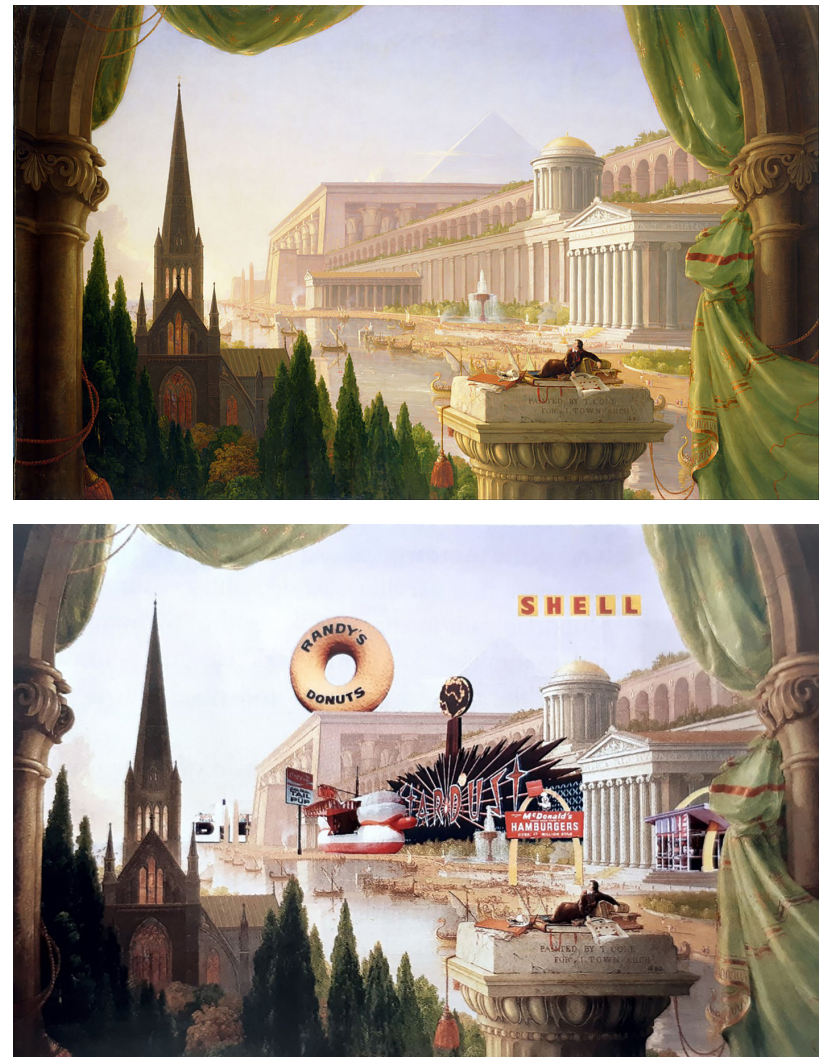

6 y 7. Thomas Cole, The Architect's Dream, 1840 y VSBA, The architect's dream augmented, en Architecture as sign and system, for a mannierist time, 2004

mar las dos cuestiones clave para observar del sueño de ciudad, es un producto histórico de la imaginación radical, insumiso con cualquier posibilidad de determinismo socioeconómico, incluyendo el determinismo del materialismo histórico, donde la consciencia individual del hombre se adquiere por lo social. Los imaginarios son representaciones o significaciones sociales cargadas de valores bien amalgamados que no se estructuran mediante axiomas. Los imaginarios son importantes puesto que acotan el ámbito de lo pensable en momentos históricos o en ámbitos culturales concretos. A diferencia de la ideología, que se limita a clases y grupos sociales, los imaginarios abarcan en conjunto la estructura e instituciones sociales. Lo que Crary y otros autores detectan es que ya no nos quedan los sueños como espacios de libertad, que la arquitectura es brazo ejecutor mediante una erótica del sueño que se libra de dar cuenta de sus actos al personificar en un ente con vida propia la 


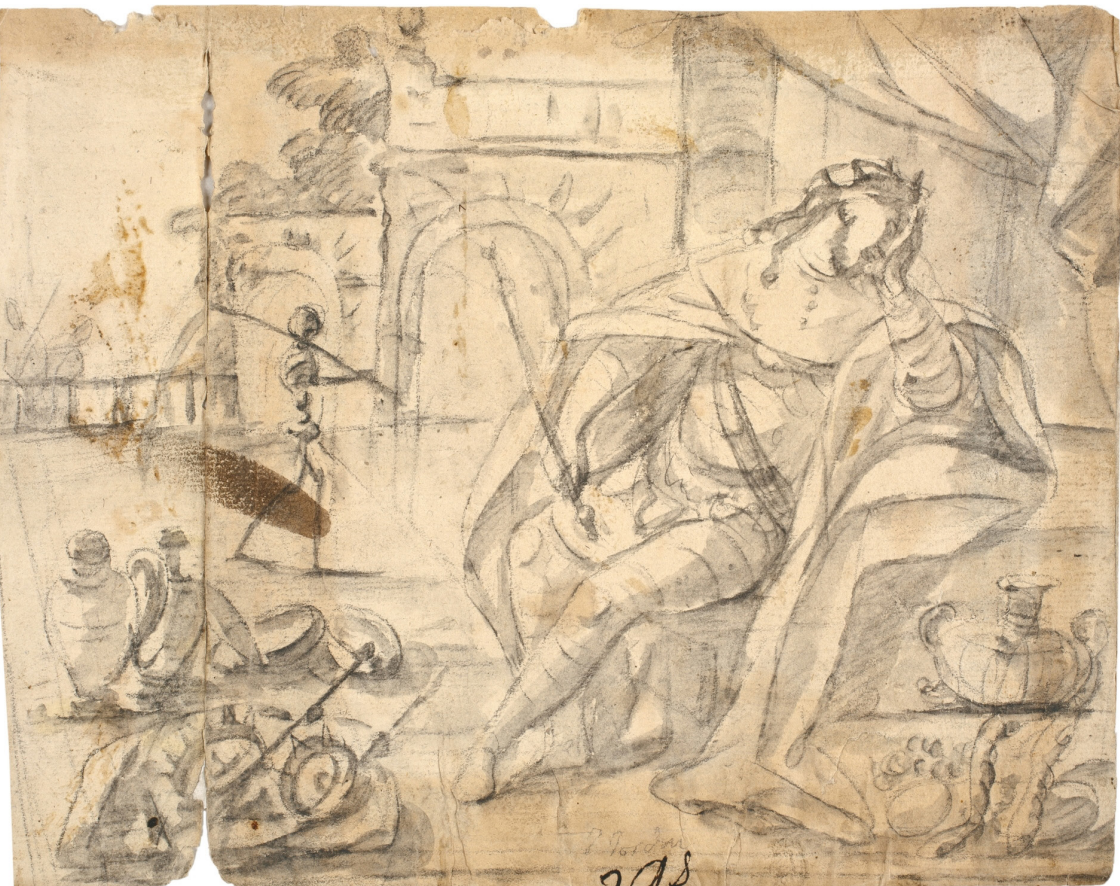

8. El sueño de un rey. Museo Nacional del Prado. Luca Giordano (atribuido) s. XVII razón y causa de sus decisiones, canalizadas como deseos irrefrenables, autoconscientes y ya, sin la necesidad del despertar.

Desde que Freud logró asociar aquello que conocíamos como «alma», o «psique» en términos psicoanalíticos, con el concepto «inconsciente», que se encuentra entre lo metafísico y lo científico (Sloterdijk y Turner, 2018), la prédica de los pastores de esta religión consiste en la promesa del paraíso terrenal que es el cumplimiento de los deseos (wish fulfillment) inalcanzables -o Wunscherfüllung-, de su libro La interpretación de los sueños (Freud y Brill, 1997) ${ }^{27}$.

Los predicadores de lo onírico son ciudadanos con poder, desde monarcas a arquitectos. Existe en el Museo del Prado de Madrid un boceto realizado con aguada y lápiz titulado Sueño de un rey, pintado por Luca Giordano, que estaba de paso por la capital española a finales del siglo XVII. Esta alegoría muestra en la composición, a la derecha, sentado y con la cabeza apoyada en una mano, a un rey con los ojos cerrados, en una suerte de alucinación hipnagógi$\mathrm{ca}^{28}$, sosteniendo un cetro en la mano. A la izquierda, sobre el suelo, coronas, joyas y vasijas. Por último, la Muerte se ve al fondo con una guadaña, bien integrada con la ciudad que emerge como promesa de lo que se ha de conseguir. Debe ser en ese momento de alucinación, previo al sueño, porque aún mantiene estable el cetro en su mano. Es el momento de confusión deseo-sueño, de creación y anhelo. Como cuando Dalí usaba un objeto pesado para su inspiración a partir del sueño, sujeto en su mano. El primer sueño es el más vívido y, una vez se han relajado los músculos, esas llaves, piedra o pequeña campana cae al suelo, rompiendo el trance y ayudando a recordar más claramente lo soñado para llevarlo al lienzo [8].

Al modo en que ese rey soñaba con construir su reino, el sueño de modernidad se hizo forma arquitectónica en la figura de Mies van der Rohe, en un sueño propio ${ }^{29}$ que se hizo colectivo, en paralelo a la pesadilla totalitaria que envolvía Europa. Cuando Mies no obtuvo respaldo político para trabajar en Alemania, Lilly von Schnitzler (Schulze y Windhorst, 2016) hizo lo indecible para favorecerlo. No tenía encargos, no tenía trabajo: «estoy en las últimas, en lo material», llegó a decir a la esposa del funcionario von Schnitzler que le había encargado el Pabellón de Barcelona. Cuando la señora von Schnitzler habló en una cena con Goebbels alabando a Mies como el mejor arquitecto de Alemania, le replicó el Ministro para llustración Pública y Propaganda del Tercer Reich que era el segundo mejor, dado que el favorito de Hitler era Paul 

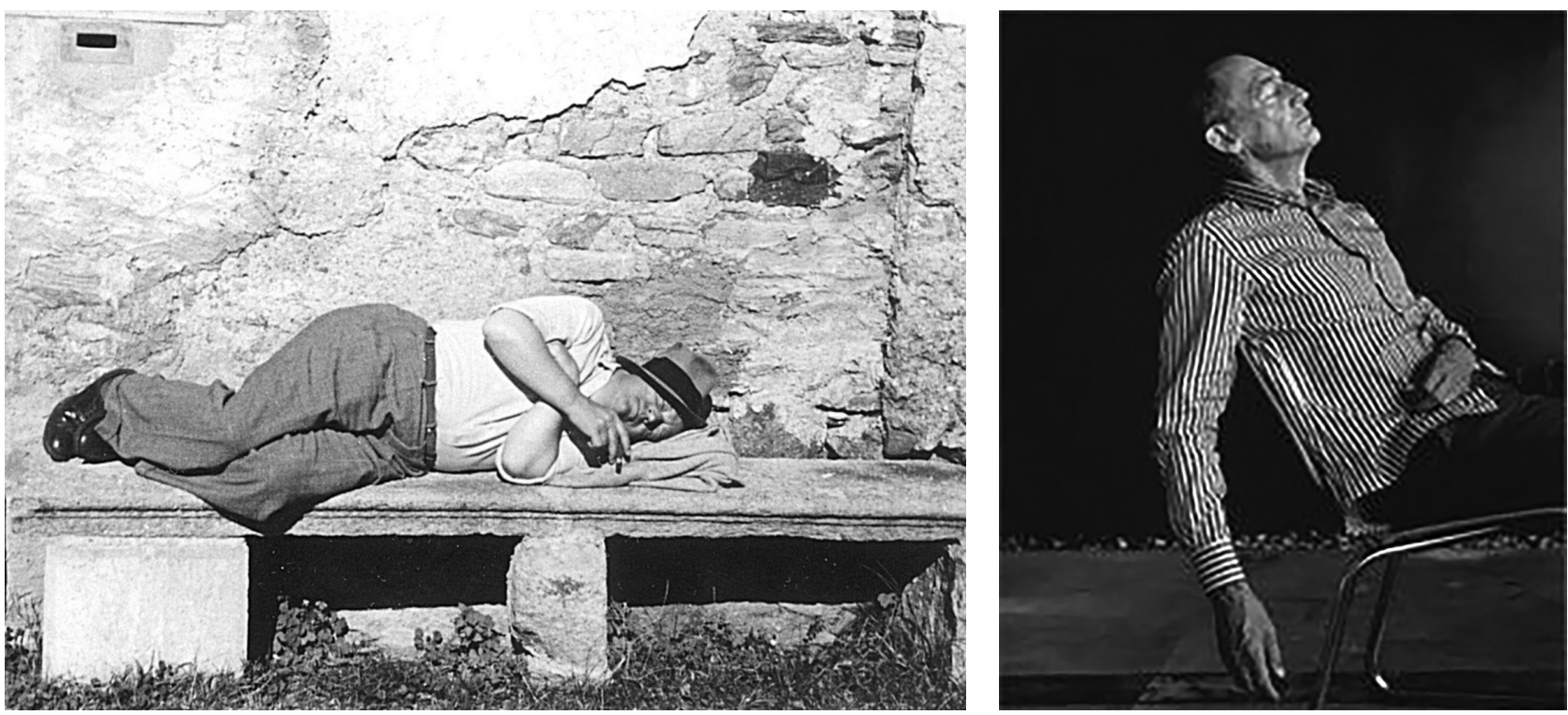

9 y 10. Mies en un viaje a Pura/Ticino. Fritz Schreiber, octubre de 1933 (Stiftung Bauhaus Dessau) y Rem Koolhaas en el Kennedy Hall's David L. Call Alumni Auditorium U. Cornell, 2005

Troost. Y añadió: «parece que usted no sabe que los estados totalitarios dependen del favor de las masas. Estamos obligados a bailar laboriosamente sobre una ola, y si la ola no nos soportase, desapareceríamos de la noche a la mañana. No puedo hacer nada por Mies, pues». Los nazis tenían su propio estado hipnagógico que mantener, como es bien sabido, su propio Gran-Danés, y la arquitectura era el fondo adecuado, como en el cuadro de Giordano, con la muerte incluida.

Mies, en 1933, se fue al cantón suizo de Ticino con Reich a dar clases a cinco estudiantes, dos de ellos con sus esposas, durante seis meses, para ganarse la vida. El ejercicio docente consistió en proyectar una casa para Mies por la zona. Hay una famosa foto de Mies, soñando el mundo por su parte, sobre un duro banco de piedra. Lleva cetro, si por él pensamos en aquel elemento pesante para lograr ampliar el recuerdo de los sueños: su permanente cigarro. La foto merece más detención si se tiene en cuenta que no dejaba publicar foto de su obra sin su previa revisión, pero para nuestros supuestos, ese mundo embrionario por el sueño está en su momento de esplendor: no hay encargos, solo dibujar y leer para condicionar el sueño que abrazaron generaciones de arquitectos con posterioridad.
De pastor a pastor, Koolhaas participa en la Triennale di Milano con la Casa Palestra. Incluía una instalación denominada Cleaning Mies' Barcelona Pavilion. 1985-1986. Como heredero del Concilio que Mies sueña en esos días suizos, el arquitecto holandés purifica como acto litúrgico lo que nos llega de ese Evangelio en el templo por excelencia de la Modernidad. Él, años más tarde, se deja fotografiar en una pequeña siesta antes de una conferencia en Cornell, en 2006, dormido en el escenario, con su cetro, un puntero láser para fijar el nuevo apostolado.

Ya no es tiempo de utopías, no tiene crédito el psicoanálisis, no se interpretan los sueños, los fantasmas no acuden para someter la asepsia de la Modernidad. Los arquitectos ya no son ni demiurgos ni marionetas, son pastores de esta religión de sueños individuales soñados por la ciudad que, a su vez, sueña, como forma de vida autónoma. Ser pastor significa reconocer la imposibilidad de alternativas, no se cuestiona la fe. Si hay herejes, no deben estar en ninguna lista, o el sueño los fagocitará. Quien sostiene cetros, sean cigarros o punteros, asume la responsabilidad de indiferenciar sueños con deseos, de hacerlos colectivos, y sumirlos en los sueños de seres incuestionables [9] y [10]. 


\section{Notas}

1 Es un término propuesto por S. Freud para designar producciones mentales imaginadas en el estado de vigilia que tienen algunas similitudes con los sueños nocturnos, y cómo los sueños despiertos apuntan a la satisfacción de los deseos.

2 Para Sloterdijk, el s. XX se caracteriza por visiones que van de la utopía en E. Bloch, al sueño en Freud y al fantasma en Derrida.

3 Žižek (2020) dirá: "Otro fenómeno extraño que podemos observar es el retorno triunfal del animismo capitalista, de tratar los fenómenos sociales como los mercados o el capital financiero como entidades vivientes".

4 Aunque la noción de antropomorfismo está atestiguada por primera vez a mediados del s. XVIII, ya desde la prehistoria nos reconocemos en otros seres. El asalto al humanismo se encuentra en la filosofía, en primer lugar, pero también la literatura o el cine, o ahora, en la inteligencia artificial.

5 Según Heidegger, el hombre no es un animal, pero tiene semejanzas conductuales con ellos, yendo a la contra de la modernidad. Es la famosa y ambigua definición del Hombre como "Pastor del Ser», donde la apertura hacia un humanismo no dominador y descentrado no ofrece oportunidades en su encierro metafísico para nuestro arquitecto-pastor. Nuestro pastor, no interesado en las acciones que hagan mundo, es un proveedor de sueños para nuevos seres.

6 En 1953, en Chicago, Nathaniel Kleitman fue pionero en la investigación sobre el sueño y su repercusión en el cuerpo. Publicó el primer estudio del sueño REM. Fue en el mismo año y ciudad que se editó por vez primera la revista Playboy, construyendo el sueño colectivo de millones de personas en todo el mundo en décadas posteriores. Ver Cartwright, 2012; Preciado, 2010.

7 Masculino en la película de Auer, y por extensión, el género que domina el ser que es la ciudad. Contrariamente, para F. de Azúa, en La invención de Caín (2015: 2731), basándose en un extracto de J. Gracq que antropomorfiza la ciudad, pero por sus oquedades, tiene un sentido más uterino y sexual femenino. Gracq habla de sueño y, sin embargo, no es el mismo sentido en nuestro supuesto de la ciudad que sueña, muy diferente del psicoanálisis del soñador.

8 En El Antiedipo (1998) Deleuze acerca el deseo al delirio, no al sueño, que es una desterritorialidad.

9 Wikipedia, «American Dream». En: <https://en.wikipedia.org/wiki/American_Dream> (fecha de consulta: 14-09-2019), y Wikipedia, "Chinese Dream». En: <https://en.wikipedia.org/wiki/Chinese_Dream> (fecha de consulta: 10-01-2019), y revista Time, China's New Dreamscape 2004, vol.163 \#18.

10 La incubación es la práctica religiosa de dormir en un área sagrada para experimentar un sueño o cura por inspiración divina.

11 Eluminateme. En: <https://www.elluminateme.com/news/neuroon-open-next-gen-sleep-wearables/\#more-1018> (fecha de consulta: 16-05-2019).

12 Neuralink. En: <https://neuralink.com/> (fecha de consulta: 16-05-2019).

13 E. Trías lo adelantó en 1976, diciendo que «la síntesis platónica de Eros y de Poíesis ha sido destruida, decantando en una doble esfera separada: esfera privada del amor, esfera pública de la producción [...]. Los pensadores y poetas más lúcidos y responsables de la modernidad tratan, sin embargo, de restaurar dicha síntesis, pero, al tener que partir de la experiencia de una escisión, se ven en la necesidad de presentarla como tarea de futuro, como idea regulativa de la acción, como utopía concreta, como sueño racional (así por ejemplo Marx o Nietzsche)» (1997: 47).

14 Zhuangzi, Chuang Tzu o Chuang Tse. Filósofo de la Antigua China (S. IV a.C.). Cita usada por Lacan para su Seminario 11, y comentado por Slavoj Žižek (2014).

15 Ilustradora de la citada obra de Koolhaas, ver como ejemplo Freud unlimited (1975).

16 Recuérdese en este momento que hay dos novelas célebres muy usadas en la historia de la arquitectura en relación con los sueños: When The Sleeper Wakes, de H. G. Wells (1899) y News from nowhere, or, An epoch of rest: being some chapters from a utopian romance, de William Morris (1889).

17 Sueño que amplificaron Venturi y Scott Brown en la famosa inserción de donuts y otras marcas publicitarias al cuadro. Ver Venturi y Scott Brown, 2004.

18 The essence of Architecture (1948): «el arquitecto debe poseer la capacidad de dar rienda suelta a su imaginación, esta habilidad que a veces se llama creatividad, a veces soñar despierto".

19 Léon Krier and Massimo Scolari, Le désespoir de Janus, 1975.

20 Archigram (1963), "Dream City Project», en Rattenbury, Kester y Fraser, Murray, Archigram Archival Project <http://archigram.westminster.ac.uk/project. php?id=41> (fecha de consulta: 23-06-2018).

21 Stanley Tigerman, Ceci n'est pas une reverie, exposición en la Graham Foundation. E. Petit escribe en el catálogo: «su arquitectura gira en torno al sueño más ambicioso de la humanidad: "construir" la mítica Casa de Ur, el Cielo, al mismo tiempo que reconoce en su arte las contingencias y limitaciones reales de realizar tal presunción».

22 El equipo francés expuso su obra en la Cite de l' Architecture \& Du Patrimoine (2009) organizada en siete secciones: paisaje, ciudad, libertad, habitar, transformación, encantamiento y sueños.

23 Rafael Aranda, Carme Pigem y Ramon Vilalta, premio Pritzker 2017, RCR. Sueño y natura_Catalonia in Venice, Instituto Ramón Llull, XVI Bienal de Arquitectura de Venecia.

24 Netflix. Abstract, 2016. Bjarke Ingels BIG: hacer arquitectura como en la película Inception.

25 Traducción de los autores.

26 Recurrimos a Castro Nogueira como actualización del pensamiento de Castoriadis.

27 Recuérdense las características de los sueños para volver a leer la cita de Boyarsky sobre Chicago: la inmediatez sensorial de la percepción consciente, una estructura compuesta y la aclaración del significado a través de la asociación libre, pero con precisión.

28 Fenómenos mentales que pueden ocurrir durante una fase de «conciencia de umbral», que incluye alucinaciones, pensamiento lúcido, sueños lúcidos y parálisis del sueño.

29 No debe considerarse aquí un exceso retórico. Pueden traerse muchos ejemplos para pensarlo en la historia de la arquitectura. Por ejemplo, en «Día y noche», Josep Llinàs (1997) dice de Mies que hacer arquitectura es algo así como expeler tras de un juego, que en Mies -Miesian nights- es deshacerse de todo salvo del dibujo. Llinàs bromea con esa desnudez: se podría dar las órdenes por teléfono para que el constructor supiera qué hacer. 


\section{Bibliografía}

AUER, John (1953), City that never sleeps, Republic Pictures, Los Angeles.

AZÚA, Félix de (2015), La Invención de Caín, Debate (Penguin Random House Grupo Editorial España), Madrid.

BERGER, John (2015), «Why look at animals?», en BERGER, John, About Looking, Bloomsbury Publishing, Londres, pp. 3-28.

BOYARSKY, Alvin (1968), «Chicago à la carte, The City as an Energy System», $A D$, n. ${ }^{\circ} 10$, pp. 10-48.

BRENNER, Neil y THEODORE, Nick (2002), «Cities and the Geographies of 'Actually Existing Neoliberalism'», Antipode, n. ${ }^{\circ} 34$, pp. $349-379$.

CARTWRIGHT, Rosalyn (2012), The twenty-four hour mind: the role of sleep and dreaming in our emotional lives, Oxford University Press, Nueva York y Oxford.

CASTRO NOGUEIRA, Luis (1997), La risa del espacio: el imaginario espacio-temporal en la cultura contemporánea: una reflexión sociológica, Tecnos, Madrid.

CASTRO NOGUEIRA, Luis (1988), «El Espacio-tiempo social. Fragmentos de ontología Política», Archipiélago: Cuadernos de crítica de la cultura, n. ${ }^{\circ} 34-35$, pp. 40-46.

CRARY, John (2013), 24/7: Late Capitalism and the Ends of Sleep, Verso, Nueva York.

DELEUZE Gilles y GUATTARI, Felix (1998), El anti-edipo: capitalismo y esquizofrenia, Paidós, Barcelona.

DERRIDA, Jacques (2008), The animal that therefore I am, Fordham University Press, Nueva York.

FREUD, Sigmund y BRILL, Abrahan Arden (1997), The Interpretation of Dreams, Wordsworth Editions, Ware.

HEJDUK, John y SHKAPICH, Kim (1985), Mask of Medusa: works, 1947-1983, Rizzoli, Nueva York.

HOLLIS, Edward (2011), The Secret Lives of Buildings: From the Parthenon to the Vegas Strip in Thirteen Stories, Granta Publications, Londres. KOOLHAAS, Remment (2014), Delirious New York: A Retroactive Manifesto for Manhattan, Monacelli Press, Nueva York.

KOOLHAAS, Remment, CHUNG, Chuihua Judy, INABA, Jeffrey y LEONG, Sze Tsung (eds.) (2001), Project on the City I: Great Leap Forward, Taschen, Köln.

KOROM, Joseph J. (2008), The American Skyscraper, 1850-1940: A Celebration of Height, Branden Books, Wellesley, MA.

LATOUR, Bruno (2007), Reassembling the social: an introduction to Actor-Network-Theory, Oxford Univ. Press, Oxford.

DESCOLA, Philippe (2008), «El tercer día. La primera sesión», en LATOUR, Bruno y GAGLIARDI, Pasquale (eds), Las atmósferas de la política: diálogo sobre la democracia, Universidad Complutense de Madrid, Madrid, pp. 179-204.

LEFEBVRE, Henri (2018), Hacia una arquitectura del placer. CIS, Centro de Investigaciones Sociológicas, Madrid.

LLINÀS, Josep (1997), «Día y noche», en LLINÀS, Josep, Josep Llinàs, Tanais Ediciones, S. A., Madrid, pp. 12-15.

MONEO, Rafael (2017), La vida de los edificios: la mezquita de Córdoba, la lonja de Sevilla y un carmen en Granada, Acantilado, Barcelona. PRECIADO, Paul B. (2010), Pornotopía: arquitectura y sexualidad en Playboy durante la Guerra Fría, Anagrama, Barcelona.

SCHULZE, Franz y WINDHORST, Edward (2016), Ludwig Mies van der Rohe: una biografía crítica, Reverte, Barcelona.

SLOTERDIJK Peter y TURNER, Christopher (2018), What Happened in the Twentieth Century?: Towards a Critique of Extremist Reason, Wiley, Cambridge (UK).

STAHL, P. J. (ed.), GRANDVILLE, Jean-Jacques (il.) (1877), Public and Private Life of Animals, S. Low, Marston, Searle \& Rivington, Londres.

TRÍAS, Eugenio (1997), El Artista y La Ciudad, Anagrama, Barcelona.

VENTURI, Robert y SCOTT BROWN, Denisse (2004), Architecture as signs and systems: for a mannerist time, Belknap Press of Harvard University Press, Cambridge, MA.

ŽIŽEK, Slavoj (2014), The Most Sublime Hysteric: Hegel with Lacan, Wiley, Londres.

ŽIŽEK, Slavoj (2020), «El coronavirus es un golpe al capitalismo a lo Kill Bill», en AMADEO, Pablo (ed.), Sopa de Wuhan. Pensamiento contemporáneo en tiempos de pandemias, Editorial ASPO [Aislamiento Social Preventivo y Obligatorio], Buenos Aires, pp. 21-28. 